\section{Welcome to the second issue of TOS forum}

$\mathrm{t}$ is a very satisfactory achievement that you are now in possession of the second issue of TOS forum. The objective is to develop the forum into a regular periodical, and we are well under way. I estimate that we shall have published TOS forum Issue 5 before the next World Conference on Sampling and Blending, which takes place in Bordeaux, June 2015-see "Messages from the Chairmen WCSB7" opposite.

The interest in publishing minor progress reports from both academic and industry projects in TOS forum is growing in a satisfactory manner (the table of contents is already half full for TOS forum Issue 3), while several other types of presentations relate to the express need for effective communication between all members of the world community of professional samplers. TOS forum was created precisely with these needs and desires in mind; so far developments could not be better.

I have a serious issue to discuss with all our readers, an issue that must not cause misunderstanding. The editor has received a couple of complaints: "There is hardly anything of interest for the mining world to be found in TOS forum". This is both trueand this is not true (sic).

True, most likely - undoubtedly because the entire mining community has just been well served by WCSB6, November 2014, Lima. Everyone that had anything important to communicate to our community had his/her say in Lima. It is still very early days after this successful conference-and more important: all types of contributions are welcome in TOS forum. Anyone from the mining industry who has anything more/new/complementary to the proceedings facility from WCSB6 to say... please just start clicking away on your keyboard. Your mining-related contribution is no farther away from TOS forum than an e-mail to ke@geus.dk-l extend a serious and warm invitation to all.

Not true, because the quite satisfactory spread of theoretical and application pieces in TOS forum Issues 1 and 2 are of meant

continued on page 4
The front page photo may pu you at first, but it is subtly connected to TOS, however. You are looking at the façade of the Lima Marriott Hotel, the venue for WCSB6 (2013).

Photo: Anne Jodon Cole

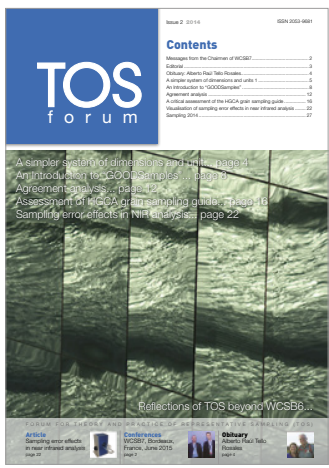

\section{Be part of the next issue of TOS forum!}

We welcome contributions to TOS forum: articles, letters, comment, news or news of PhD projects for the PhD Presentations column.

TOS forum Editor, Kim Esbensen, would be pleased to discuss any ideas you may have and to receive your contributions.

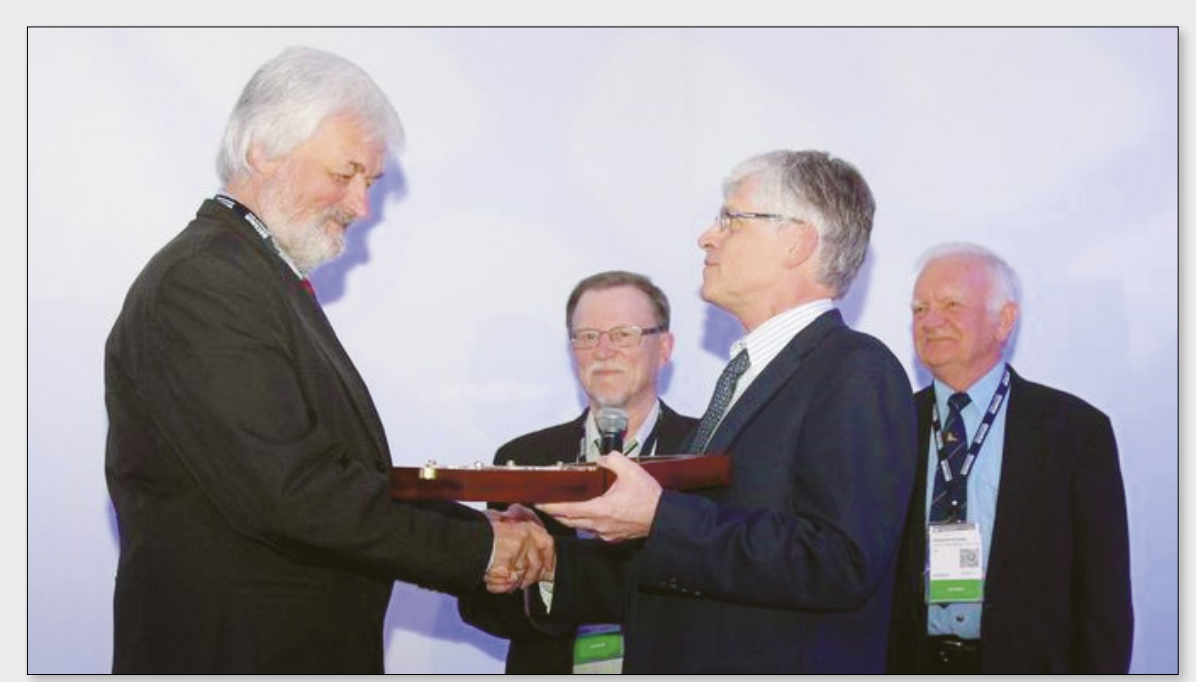

Presentation of the 2013 Pierre GY Sampling Gold Medal at WCSB6, 24 November 2013, Lima.

\section{EDITOR}

Kim H. Esbensen (Geological Survey of Denmark and Greenland (GEUS), Copenhagen, and ACABS research group, Aalborg University, campus Esbjerg, Denmark; ke@geus.dk)

\section{PUBLISHER}

lan Michael (ian@impublications.com)

\section{2014 IM Publications LLP}

6 Charlton Mill, Charlton, Chichester, West Sussex PO18 OHY, UK.

Tel: +44-1243-811334;

Fax: +44-1243-811711;

E-mail: subs@impublications.com

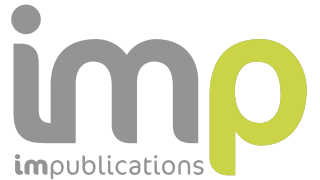

TOS forum will be available on subscription in 2015. Visit www.impublications.com/tos-forum for details.

Editorial correspondence to Kim Esbensen, ke@geus.dk. All production correspondence should be sent to TOS forum, 6 Charlton Mill, Charlton, Chichester, West Sussex PO18 OHY, UK, Tel: +44(0)1243-811334, Fax: +44(0)1243-811711, e-mail: ian@impublications.com. 
continued from page 3

to be of significant inspirational value for all who are interested in sampling, of course also for the mining world! It is the very same principles of representative sampling that undermines each-and-every entry in the forum. That said, the Editor shall always be hard at work seeking out new, novel, different angles and application fields where TOS shows its value-surely this type of pushing the envelope can only be of interest to absolutely all with a commitment to disseminate TOS.

While the present issue is still somewhat the result of invitations and solicitations regarding the subject-matter horizon (and while such an active role will continue on behalf of the editorial office), it is hoped that this gradually will be taken over by a drive for wanting "my contribution" in TOS forum as well. It is clear to the Editor and the Publisher that it is our solemn obligation to facility such a development, and we assure the readership that no efforts shall be spared in this regard. It is the goal that by WCSB7,
TOS forum has developed to be both a necessary and the sufficient imperative for a revolution in the ability for the world community of sampling to be in close contact at all times between the biannual WCSBs.

The Editor wishes to thank the governing body in charge of selecting recipients for the Pierre Gy Sampling Gold Medal for receiving this award at WCSB6, Lima 2014. This is an immense honour, one that cannot be surpassed in my personal scientific endeavour-ever. It is the greatest possible inspiration and drive to continue to serve the world sampling community in the best possible fashion.

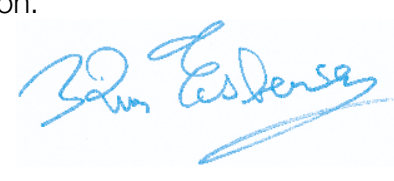

Kim Esbensen

\section{Final words from our Publisher, IM Publications}

Putting together any publication, but especially a new one, is a lot of work, as Kim has discovered and alluded to above! Beyond the content-the words and images-the important matter of commercial success needs to be considered, without which any long-term publication is impossible. There are only two sources of income: subscriptions and sponsorship. The former is familiar to us all! The latter may be direct sponsorship or advertising. TOS forum has been fortunate that sponsorship has been available to offset some of the costs in its publication and distribution so far. In the end though, TOS forum is likely to need to be of sufficient interest and value to its readers that they will subscribe. Until WCSB7, TOS forum will remain free, but at or soon after that meeting, a decision will need to be made about its longer-term viability.

In the meantime, we need to work to ensure that TOS forum meets the needs of the entire TOS community, but also the wider analytical community who may not appreciate fully the importance of representative sampling. I hope you will help Kim and us in our endeavours to achieve this.

Ian Michael 